\title{
OS ELOS INVÍSIVEIS ENTRE DESIGUALDADE ESTRUTURAL E ARBOVIROSES NO BRASIL: UM DEBATE A LUZ DOS PRINCIPIOS DE PROMOÇÃO DA SAÚDE
}

\author{
*Andreya Dessoles Marques, Ana Flávia Freitas de Miranda Coêlho, Jaylane da Silva Santos, \\ Luciene de Souza Santos Albuquerque, Kátia Cristina Barbosa Ferreira; Rozileide Martins \\ Simões Candeia, Lúcia Gomes de Souza Silva, Janaína Medeiros de Oliveira Sousa, Maria \\ Carolina Salustino dos Santos, Jamayana Lima de Souza Amaral and Leonardo de Araújo e Mota
}

Mestre em Desenvolvimento Regional pela Universidade Estadual da Paraíba, Especialista em Saúde mental e Atenção Psicossocial pela Fiocruz, Graduação em Serviço Social, pela Universidade Estadual da Paraíba, Atuante na Estratégia de Saúde da Família e na Assistência Hospitalar

\section{ARTICLE INFO}

Article History:

Received $20^{\text {th }}$ June, 2021

Received in revised form

$17^{\text {th }}$ July, 2021

Accepted $06^{\text {th }}$ August, 2021

Published online $29^{\text {th }}$ September, 2021

\section{Key Words:}

Arboviroses; Promoção da Saúde;

Determinação Social das Arboviroses;

Brasil.

*Corresponding author:

Andreya Dessoles Marques

\begin{abstract}
Problematizar o modelo de controle as arboviroses a luz dos conceitos e paradigmas que norteiam a Nova Promoção da Saúde no Brasil. Fez uso da pesquisa documental e bibliográfica, constituída por meio da análise de documentos do Ministério da Saúde, Organização Mundial da Saúde (OMS), além de outras fontes de dados oficia, datadas entre os anos de 2015 a 2018. Realizou-se ainda, pesquisa nos sites: "Google acadêmico" e "Scielo", utilizando descritores como: "Arboviroses no Brasil", "Arboviroses", "Promoção da Saúde", "Determinação Social das Arboviroses". Entende-se assim que as epidemias por arboviroses no contexto brasileiro é a expressão latente do modelo de sociabilidade capitalista, na qual todos os recursos humanos e materiais estão voltados para atender as necessidades do próprio capital em detrimento das necessidades mais elementares do ser humano.
\end{abstract}

Copyright (C) 2021, Andreya Dessoles Marques et al. This is an open access article distributed under the Creative Commons Attribution License, which permits unrestricted use, distribution, and reproduction in any medium, provided the original work is properly cited.

Citation: Andreya Dessoles Marques, Ana Flávia Freitas de Miranda Coêlho et al. "Os elos invísiveis entre desigualdade estrutural e arboviroses no brasil: um debate a luz dos principios de promoção da saúde”, International Journal of Development Research, 11, (09), 50391-50397.

\section{INTRODUCTION}

As arboviroses são caracterizadas como doenças infecciosas virais de evolução geralmente benigna, de transmissão vetorial pelo mosquito Aedes Aegypti, constituem um grave problema de saúde pública no Brasil, pois trazem em sua dinâmica de transmissão, condicionantes biológicos, comportamentais, ecológicos, políticos e econômicos (SANTOS, AUGUSTO, 2011). Tal fato pressupõe a necessidade da interligação de diversos esforços na perspectiva de se construir uma política pública que objetive superar o quadro de iniquidades em saúde que circunda o contexto de tais epidemias. A centralidade dada ao vetor (o mosquito) nas políticas que objetivam lidar com as epidemias causadas por arbovirus no Brasil escamoteia uma lista de adversários da saúde pública. Entende-se que o contexto intertropical do país aliado às péssimas condições sanitárias presentes em boa parte das cidades brasileiras, em um processo de urbanização acelerado ocasionou um processo de favelização dos grandes e médios centros urbanos, o que levou a uma distribuição espacial assimétrica de serviços sociais básicos e infraestrutura urbana, como: água, esgotamento sanitário, coleta de lixo, favorecendo a propagação do aedes nas regiões mais vulneráveis do país, sugerindo uma correlação entre as epidemias por arbovirus e as condições matérias de existência. Mediante o exposto este estudo busca problematizar o modelo de controle as arboviroses à luz dos conceitos e paradigmas que norteiam a Nova Promoção da Saúde no Brasil, como uma alternativa ao modelo tradicional centrado na concepção biomédica do problema. O percurso metodológico para construção deste estudo fez uso da pesquisa documental e bibliográfica, constituída por meio da análise de documentos do Ministério da Saúde, Organização Mundial da Saúde (OMS), além de outras fontes de dados oficiais, datadas entre os anos de 2015 a 2018. Realizou-se ainda, pesquisa nos sites "Google acadêmico" e "Scielo", utilizando descritores como: "Arboviroses no Brasill", "Arboviroses", "Promoção da Saúde", 
"Determinação Social das Arboviroses". O critério de inclusão para selecionar os artigos deu-se pelo maior número de acessos aos escritos. Ainda tomamos como base textos de diversos autores que estudam políticas públicas no sentido de compreender lacunas e particularidades das políticas destinadas ao controle das arboviroses no Brasil. Espera-se que os resultados apresentados possam oferecer elementos capazes de fortalecer o elo entre adoecimento, desigualdade estrutural e arboviroses no Brasil, relação ainda incipiente no campo das ciências humanas.

\section{CONDIÇÕES DE VIDA E ADOECIMENTO POR ARBOVIROSES NO BRASIL}

As arboviroses são doenças virais transmitidas ao homem por insetos. Os arbovírus (Arthropod-borne virus) são assim denominados por possuírem ciclo replicativo nos artrópodes hematófagos e por serem repassados destes para os humanos através de sua picada (LOPES, NOZAWA, LINHARES, 2014). O principal vetor das arboviroses tem sido o mosquito Aedes aegypti, podendo transmitir a Febre Amarela, Dengue, Chikungunya e a Zika (JOHANSEN, 2014; SEGATA, 2016). A presença dos arbovírus no Brasil e a preocupação com seus impactos na saúde da população não são recentes. $O$ Instituto Oswaldo Cruz afirma que o mosquito Aedes aegypti chegou ao país no período colonial através dos navios que aportavam em solo brasileiro, sendo a Febre Amarela a primeira doença a ser transmitida por ele. No atual contexto epidemiológico brasileiro circulam vários arbovírus, como Mayaro (MAYV), Encefalite Equina Venezuelana (VEEV), Encefalite do Leste (EEEV), Rocio (ROCV), Chikungunya (CHIKV), Zíka (ZIKV) e Dengue (DENV). No entanto, os arbovírus de maior circulação são: DENV, CHIKV e ZIKV, além do vírus da Febre Amarela e de outros com potencial de disseminação no país (Lopes, 2014). Segundo a ABRASCO (2016), o crescente número de epidemias por arboviroses no país é resultante das péssimas condições sanitárias em que cresceu boa parte das cidades brasileiras, aliado as condições climáticas e ambientais favoráveis.

O contexto ambiental intertropical, o aumento da população urbana, a pressão exacerbada sobre a infraestrutura urbana, como acesso à água e gestão de resíduos, contribuíram para a multiplicação de criadouros de larvas de A. aegypti, tornando os territórios urbanos altamente vulneráveis em termos de segurança sanitária. Desta forma, em meados de 2014, o Brasil foi atingindo por três epidemias sucessivas de arboviroses. Neste período os vírus da Dengue (DEN), Zika (ZIKV) e Chikungunya (CHIK) circulavam pelo país representando grave risco à saúde da população. A partir de 2015, o aumento de casos de síndromes neurológicas e o nascimento de crianças com microcefalia associados ao vírus Zika converteu o Brasil no epicentro de uma emergência sanitária de relevância internacional e transformou o mosquito "aedes" no maior inimigo da Saúde Pública (VENTURA, 2016, PIMENTA, 2016). Já em 2017, o surto de Febre Amarela que acometeu o estado de Minas Gerais, seguido de várias notificações do vírus no estado de São Paulo em 2018, trouxe um novo enfoque científico para o tema, buscando compreender os fatores determinantes do problema, fato que demonstra a vulnerabilidade em termos sanitários do território Brasileiro no tocante as epidemias ocasionadas por arbovirus (SÃO PAULO, 2018; BRASIL, 2017). A entrada desses arbovírus em países já endêmicos para a dengue como é o caso brasileiro pode trazer um verdadeiro colapso para os serviços de saúde, principalmente ao serem afetados por epidemias simultâneas. Neste sentido os dados apontam para uma dramática disseminação de dengue nas Américas nas últimas décadas, com mais de dois milhões de casos notificados em 2015 (até 8 de dezembro de 2015), sendo 1,5 milhão no Brasil, com 811 óbitos e taxa de incidência de 763 para 100 mil habitantes, tais resultados são suficientes para ter noções da proporção da infestação de apenas uma dessas arbovisores $1^{1}$. No Brasil, os casos da doença vêm adquirindo proporções alarmantes nos últimos anos, conforme demonstra a figura abaixo:

${ }^{1}$ Pan American Health Organization. Dengue. Washington (DC); s.d [citado 2015 dez 22]. Disponível em: http://www.paho.org/hq/index.php? option $=$ com_topics\&view $=$ article\&id $=1 \&$ Itemid $=40734$

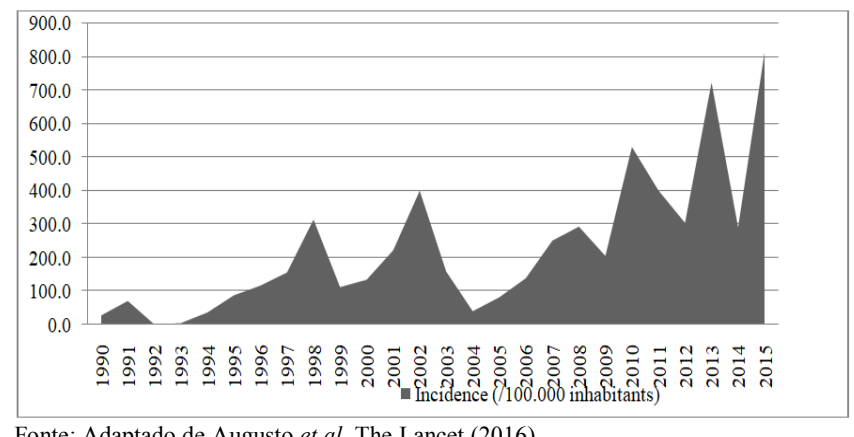

Fonte: Adaptado de Augusto et al. The Lancet (2016).

Figura 1. Incidência dos casos de dengue no Brasil entre (1990 - 2015)

Além do aumento no número de casos de Dengue, conforme observado na ilustração acima, entre os anos de 2015 e 2016, foram registrados 282.019 casos confirmados de Zika e Chikungunya e 1.500.535 casos suspeitos de Dengue no Brasil. Em 2017, foram confirmados 182 casos de infecção pelo Zika vírus e 24 mortes relacionadas ao vírus e outras etiologias infecciosas (BRASIL, 2017). Dentre os estados mais afetados encontra-se o Nordeste, apresentando em 2017, 47, 9\% casos suspeitos de arboviroses, tento 569 dos seus municípios impactados com casos de óbitos por arboviroses (BRASIL, 2017). Os impactos causados nesta região do país pelas epidemias sugerem uma correlação entre adoecimento por arbovírus e as condições materiais de existência daquela população. Nesse sentido um grande desafio é posto para a saúde pública: o diagnóstico de novas arboviroses que chegam ao Brasil, entre elas o Zíka Vírus (ZYKV), que assolou o Nordeste brasileiro entre os anos de 2015 e 2016. As baixas condições sanitárias, os problemas ambientais, a urbanização desordenada e demais eventos migratórios como a Copa do Mundo de 2014 contribuíram para a sua infestação no país (BRASIL, 2016b; VASCONCELOS, 2015). Ainda em 2015, o aumento de casos de síndromes neurológicas e o nascimento de crianças com microcefalia associadas ao vírus, gerou grande preocupação para as autoridades sanitárias de todo o mundo. Até fevereiro de 2016, haviam 270 casos confirmados em bebês brasileiros de síndrome congênita pelo ZYKA e outros 3.449 suspeitos desde 2015 (FREITAS; VON; ALMEIDA, 2016). O mapa abaixo demonstra a distribuição espacial no Brasil dos casos microcefalia ou alterações do sistema nervoso central relacionado ao vírus.

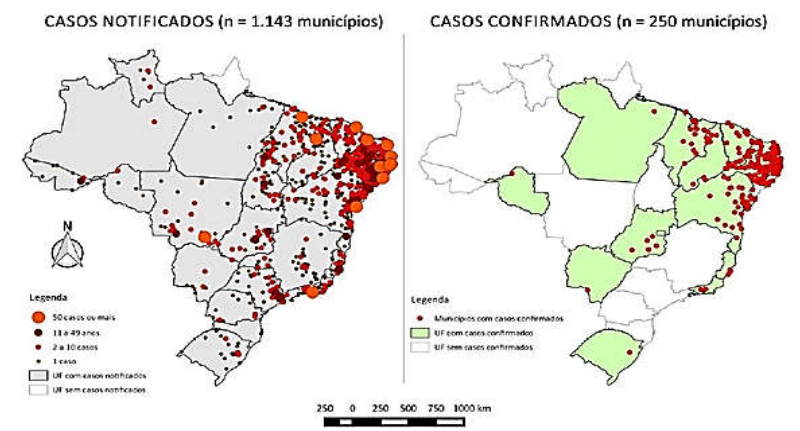

Fonte: Ministério da Saúde e Secretárias Estaduais de Saúde (2016).

Figura 2. Distribuição espacial dos casos de Microcefalia e Alterações do Sistema Nervoso central no Brasil (2015-2016)

O mapa acima demonstra a distribuição espacial dos casos de microcefalia e alterações do sistema nervoso central no Brasil até a Semana Epidemiológica 08/2016, no qual fica evidente que a grande maioria dos casos se deu na região Nordeste do país, região que apresenta o menor Índice de Desenvolvimento Humano (IDH) e um dos menores índices em termos de Produto Interno Bruto (PIB) do país, associado a uma densidade população de $28 \%$ dos habitantes brasileiros (IBGE, 2010). Aliado a esses baixos indicadores, a região ainda apresenta segundo o Sistema Nacional de Informações Sobre Saneamento (SNIS, 2017) o menor índice de saneamento básico do país. Essa conjuntura é apontada em diversos estudos como um contributo para o crescente aumento das epidemias ocasionadas por arbovírus (JOHANSEN, 2014; ABRASCO, 2016). Desta forma, os 
números demonstram que a negligencia com relação a estes serviços por anos a fio permitiram a proliferação do mosquito aedes e rápida disseminação de arboviroses transmitidas por este vetor, impactando especialmente nas regiões mais periféricas do Brasil. Os dados do Ministério da Saúde (BRASIL, 2017) ainda corroboram com a correlação entre adoecimento e pobreza, pois revelam que o maior número de casos de arboviroses e óbitos em sua decorrência entre os anos de 2015 a 2017 foi registrado nas regiões Norte e Nordeste do Brasil, regiões mais vulneráveis do país em termos de infraestrutura urbana, conforme revela a Tabela 1:

Tabela 1. Casos de arboviroses no Brasil de 2015 a 2017:

\begin{tabular}{|l|l|l|l|l|}
\hline \multirow{2}{*}{} & \multicolumn{2}{|l|}{$\begin{array}{l}2015-2016 \\
\text { (acumulado) }\end{array}$} & \multicolumn{2}{l|}{$\begin{array}{l}\text { 2017 } \\
\text { (acumulado } \\
\text { até 24/05/2017) }\end{array}$} \\
\cline { 2 - 5 } & $\begin{array}{l}\text { Municípios } \\
\text { com casos }\end{array}$ & $\begin{array}{l}\text { Municípios } \\
\text { com óbitos }\end{array}$ & $\begin{array}{l}\text { Municípios } \\
\text { com casos }\end{array}$ & $\begin{array}{l}\text { Municípios } \\
\text { com óbitos }\end{array}$ \\
\hline Norte & 40 & 16 & 26 & 4 \\
\hline Nordeste & 569 & 87 & 65 & 9 \\
\hline Centro-Oeste & 53 & 8 & 26 & 5 \\
\hline Sudeste & 74 & 11 & 56 & 5 \\
\hline Sul & 19 & 2 & 9 & 1 \\
\hline BRASIL & 755 & 124 & 182 & 24 \\
\hline
\end{tabular}

Fonte: Ministério da Saúde, 2017 (Adaptado).

A sugestiva correlação entre condições de vida precárias e adoecimento acaba sendo escamoteada pela lógica do capital. Com relação às sucessivas epidemias de arboviroes que acometem o Brasil, historicamente as medidas empregadas atuam sobre o problema visando eliminar criadouros e focos do mosquito, ignorando suas causas estruturais, por vezes advindas de um modelo de urbanização desigual no qual imergiu boa parte das cidades brasileiras. De acordo com o Ministério das Cidades (2013), o modelo de urbanização brasileiro produziu nas últimas décadas cidades caracterizadas pela fragmentação do espaço e pela exclusão social e territorial (BRASIL, 2016). Entende-se assim, que o foco dado ao aedes esconde um cotidiano urbano marcado por assimetrias entre as classes sociais que habitam a citadina que se evidenciam através de "problemas relacionados à sua infraestrutura, tais como: baixa cobertura na coleta de lixo e intermitência no abastecimento de água, estes são fatores que comprometem a efetividade dos métodos tradicionais de controle" (ZARA et al., 2016, p. 1). Compreende-se que a solução do problema passa pela articulação de várias políticas de forma intersetorial e integrada e por mudanças estruturais na base material de produção. Tal situação demonstra a necessidade de problematizar a relação saúde-doença no sentido de ultrapassar a lógica biomédica que embasa as políticas públicas de saúde no Brasil, especialmente aquelas destinadas ao controle de vetores. Neste sentido, a seção a seguir busca problematizar tal modelo e discutir a temática em questão so enfoque da Promoção da Saúde.

\section{O MODELO BIOMÉDICO DE PROMOÇão DA SAÚDE E SUAS CONTRADIÇÕES}

O presente estudo compreende a problemática da epidemia por arboviroses no Brasil como fenômeno social e multicausal. O adoecimento é um processo coletivo, fruto do modo como vivemos, adoecemos, trabalhamos, consumimos, enfim da maneira como levamos a vida social (ABRASCO, 2016). Nessa perspectiva a investigação, considera a Produção Social da Saúde ${ }^{2}$ como referencial teórico de discussão no qual abrange a coletividade e o caráter histórico-social do processo saúde-doença, visando ultrapassar a mera discussão de dados epidemiológicos individuais, o que propicia

\footnotetext{
${ }^{2}$ A promoção da saúde é uma proposta pública mundial contemporânea na saúde pública disseminada pela OMS desde 1984, constituindo-se como um novo paradigma e que este se contrapõe ao modelo flexeneriano que se expressa através do individualismo (atenção individual), da especialização, da tecnologização e do curativismo na atenção à saúde, predominantes, até então, nas práticas de saúde. Para mais informações sobre o tema ver, RABELLO (2006).
}

explicitar a relação entre o biológico e o social. Buscando problematizar o tema a partir do conceito de determinação social da saúde e dos princípios que norteiam a proposta de Promoção Social da Saúde, que constituem princípios teóricos do pensamento crítico que fundou a saúde coletiva e mais tarde constituiria a base do movimento da Reforma Sanitária Brasileira. O conceito da determinação social da saúde, respaldada no referencial teórico de base marxista.

Tal abordagem epistemológica se contrapõe ao modelo biomédico, que percebe o ser humano como apenas um corpo, uma "máquina" isolada a ser consertada pela medicina moderna. Tal perspectiva defende que a saúde está relacionada à organização da vida social, com base no trabalho e na reprodução social. Tal abordagem não nega a determinação biológica das condições de saúde, contudo, busca precisar seu peso em face dos determinantes comportamentais e sociais (TEXEIRA, 2009). No campo político essa perspectiva desperta para a questão da responsabilidade do Estado, no sentido de ampliar o acesso aos serviços de saúde de forma universal, além de promover melhores condições de vida para a população através da integração entre políticas sociais e econômicas, compreendendo a necessidade de intervir sobre o meio em que vivem as pessoas para que estas possam gozar de saúde.

Desde os tempos mais remotos compreende-se a intrínseca relação entre a saúde humana e o meio à sua volta. Porém, na modernidade entre o final do século XIX até meados do século XXI, houve um grande estímulo à biologização da saúde, em detrimento dos fatores sociais e ambientais (RIBEIRO, 2004; GOMEZ; MINAYO, 2006). Todavia, em contraponto ao modelo biomédico, em 1948 a Organização Mundial da Saúde (OMS) estabeleceu o conceito universal, que compreende a saúde como um estado de completo bem-estar físico, mental e social e não apenas a ausência de doença. Contudo Mas Ribeiro (2016) revela que, apesar do avanço teórico e conceitual representado por tal concepção, as políticas de saúde em nível global seguem operando campanhas sanitárias predeterminadas contra doenças específicas, ignorando as assimetrias nas condições de vida e saúde entre os países membros da OMS. Somente na década de 1970 a América Latina passa a preocupa-se com a relação entre as questões sociais e a saúde. No Brasil, na mesma época tal associação toma corpo com a emergência no campo da Saúde Coletiva através dos fundamentos teóricos do Movimento de Reforma Sanitária em curso na época. A partir de 1978, na Conferência Internacional de Cuidados Primários em Saúde, realizada pela OMS em Alma-Ata, surge a concepção moderna de Promoção da Saúde (PS), e no seu arcabouço emerge a crítica ao modelo centrado na medicina assistencial privada e biomédica (WESTPHAL, 2007). Em virtude de tal discussão, segundo Buss (2003) a saúde passa a ser vista a partir de suas multideterminações, sendo associada às condições adequadas de alimentação, moradia, educação, trabalho e cuidados de saúde, fatores que estão diretamente relacionados à qualidade de vida.

Na década de 1980, diante do contexto neoliberal, destaca-se a realização I Conferência Internacional sobre PS, realizada em Ottawa/Canadá, realizada pelo Ministério da Saúde e a OMS, apresentando contribuições valiosas para a construção do movimento em torno da Nova Promoção da Saúde (NPS). Porém, Buss (2003) destaca que embora os princípios da NPS tenham contribuído para adoção de ações político-interssetoriais, estes apresentam como centro da discussão à corresponsabilidade do indivíduo sobre sua própria saúde ${ }^{3}$, refletindo em seu arcabouço o contexto de desreponsabilização do Estado frente às políticas sociais vivenciada

\footnotetext{
${ }^{3}$ A mencionada Conferência define cinco campos da NPS: a) políticas públicas saudáveis; b) criação de ambientes favoráveis; c) reforço da ação comunitária; d) desenvolvimento de habilidades pessoais; e) reorientação dos serviços de saúde (BRASIL, 2002). São também definidos como princípios da NPS: a concepção "holística" de saúde; a equidade; a intersetorialidade; o empowerment; a participação social; as ações multi-estratégicas; a sustentabilidade (OMS, 1998).
} 
na época. Entende-se que, embora a NPS seja palco de polissemias e tensões teóricas e filosóficas, sua crítica ao modelo biomédico constitui um contributo a epidemiologia crítica na medida em ela ultrapassa o raciocínio epidemiológico tradicional centrado na doença e seus agentes infecciosos e passa a contemplar e correlacionar esses fatores com aspectos da organização política e social da sociedade. No caso específico das epidemias ocasionadas por arbovírus, este campo de saber pode contribuir para (re) formulação de políticas capazes de abranger as diversas dimensões da relação saúde-doença. Assim, a grande contribuição desta proposta se dá pela interpretação do processo saúde-doença dá relevância aos processos mais gerais da sociedade e sua relação recíproca com processos particulares. Ocorre ainda o reconhecimento de distintas dimensões que compõem o real, sujeitas às suas leis naturais, porém não separadas, mas dialeticamente relacionadas às sociais. Os estudos epidemiológicos dessa corrente contemplam em sua análise as dimensões do geral, do particular e do singular, explicadas por Breilh e Granda (1983) a seguir.

a) Existe uma dimensão estrutural, formada pelos processos de desenvolvimento da capacidade produtiva e das relações sociais que operam no contexto onde apareceu um dado problema epidemiológico. O estudo deste tipo de processos explica ao epidemiólogo quais as tendências sociais mais importantes e as formas principais da organização coletiva; b) existe uma dimensão particular formada pelos processos ditos de reprodução social, isto é, aqueles relativos à forma específica de produzir e consumir de cada grupo socioeconômico. A investigação desses processos serve ao epidemiólogo como elemento interpretativo de enlace entre os fatos e mudanças estruturais e suas consequências individuais de saúdedoença; constitui assim um nível intermediário do estudo que explica o padrão de vida do grupo como base para explicar achados empíricos de doença ou saúde nos indivíduos que o compõe; c) existe uma dimensão individual, formada pelos processos que, em última instância levam a adoecer ou morrer ou que, ao contrário, sustentam a normalidade e o desenvolvimento somáticos e psíquicos. As medidas e análises que o epidemiólogo realiza em séries de indivíduos classificados como sadios e doentes constituem a informação, no nível do concreto-empírico, utilizada na comparação com as inferências epredições estabelecidas com base nos dois níveis anteriores do estudo (p. 40).

Nessa abordagem entende-se o processo saúde-doença através de suas várias dimensões, nas quais as mais complexas delimitam as de menor complexidade, sendo a determinação dialética da totalidade a de maior complexidade, referindo-se aos processos mais gerais da vida em sociedade.Tal análise constitui um avanço sobre a epidemiologia de base positivista, na qual tradicionalmente as investigações epidemiológicas buscavam conexões entre variáveis isoladas sob o princípio da causalidade, atuando ao nível de processos singulares, portanto operando apenas no âmbito do aparente, da realidade fenomênica e reconhecendo apenas as leis causais. O interesse em compreender a problemática dos arbovirus no Brasil a partir dos conceitos que alicerçam a Promoção da Saúde (PS) deriva da necessidade de perceber o processo saúde-doença como inerente à própria produção e reprodução social da vida em sociedade, em um esforço dialético para compreensão do fenômeno e na consequente superação da visão reducionista que opera no modelo de saúde em curso (SEMAJA, 2000). Neste sentido (Vasconcelos; Schmaller, 2014; Nunes, 1989) revelam que a PS constitui assim uma crítica à hegemonia biomédica, tanto no que se refere à organização dos serviços de saúde no âmbito macropolítico, assim como na integração de políticas sociais e econômicas, na perspectiva de minimizar as desigualdades sociais, no tocante as arboviroses que podem atuar como coadjuvantes nesse processo. Entende-se, dessa forma, que as epidemias por arboviroses no contexto brasileiro são a expressão latente do modelo de sociabilidade capitalista, na qual todos os recursos humanos e materiais estão voltados para atender as necessidades do capital em detrimento das necessidades mais elementares do ser humano. As marcas deste processo encontram-se representadas através da crise ambiental, da favelização das cidades e da degradação das condições de vida e habitação no Brasil. No tocante as respostas políticas direcionadas as epidemias por arbovírus, à medida que as políticas centralizam seu foco no controle ao aedes, elas assumem um caráter biológico e individual que escamoteia uma teia de relações sociais assimétricas que se estabelecem perante a lógica do capital, favorecendo a mercantilização da vida, pois mesmo em face do insucesso dos métodos tradicionais de controle, estes continuam a serem empregados no Brasil. Assim como destaca Augusto, et al, (1998), entende-se que estas ações voltam-se para atender os interesses das indústrias química, farmacêutica e de outros bens e serviços privados de saúde, servindo fielmente aos interesses do capital. A partir dos princípios norteadores da PS torna-se salutar problematizar o modelo de controle ao aedes utilizado no Brasil. Neste sentido a próxima sessão dedica-se a problematizar este paradigma à luz da compreensão ampliada do processo saúde-doença.

\section{EQUIVOCOS E DESAFIOS DA POLITICA DE CONTROLE AO AEDES}

Segundo Martins (2016) e Labra (1985), historicamente o Aedes Aegypti vem sendo protagonista de várias epidemias no Brasil. Transmitindo desde da Febre Amarela nos anos de 1950 até o Zyka Vírus nos últimos 3 anos, além de outras diversas arboviroses transmitidas por este vetor. Em meados da década de 1950 o mosquito foi erradicado no país através de uma verdadeira operação de guerra comanda pelo sanitarista Oswaldo Cruz. Mas, em meados dos anos de 1980, o mosquito resurgiu e disseminou a Dengue por todo o território nacional. Desde então, as políticas públicas de saúde destinadas ao combate/e ou controle das arboviroses vêm operando no sentido de controlar a disseminação do vetor, fundadas em apelos sucessivos à população para eliminar criadouros e focos de âmbito doméstico. Todavia, essas alternativas não vêm conseguindo atingir seu objetivo e o país continua a sofrer com surtos sucessivos de arboviroses. Segundo (Zara, et al, 2016) sinteticamente os principais mecanismos de controle utilizados são: os meios mecânicos, biológicos e químicos. A seguir detalharemos tais mecanismos.

Controle mecânico: consiste na adoção de práticas capazes de eliminar o vetor e os criadouros ou reduzir o contato do mosquito com o homem. As principais atividades de controle mecânico envolvem a proteção, a destruição ou a destinação adequada de criadouros, drenagem de reservatórios e instalação de telas em portas e janelas. Controle biológico: é baseado na utilização de predadores ou patógenos com potencial para reduzir a população vetorial. Entre as alternativas disponíveis de predadores estão os peixee os invertebrados aquáticos, que comem as larvas e pupas, e os patógenos que liberam toxinas, como bactérias, fungos e parasitas.Outra alternativa é a utilização do Bacillus thuringiensis israelensis (Bti), um bacilo com potente ação larvicida, por sua produção de endotoxinas proteicas. Entretanto, apesar de o Bti ser eficaz na redução do número de Aedesimaturos nos recipientes tratados em curto prazo, não há evidências de que esse método isolado possa impactar na redução da morbidade da dengue em longo prazo. Controle químico: consiste no uso de produtos químicos, que podem ser neurotóxicos, análogos de hormônio juvenil e inibidores de síntese de quitina,para matar larvas e insetos adultos. É um tipo de controle recomendado mediante uso racional e seguro para o meio ambiente e para a população, complementar às ações de vigilância e manejo ambiental, devido à possibilidade de seleção de vetores resistentes aos produtos e da geração de impactos ambientais (ZARA, el al, p 393, 2016).

Desta forma entende-se que as políticas públicas de controle as arboviroses operam de forma paliativa pois são centralizadas no vetor, objetivando sanar a crise, sendo estabelecidas de forma verticalizada e desconsiderando as particularidades do caso brasileiro, que apresenta dimensões continentais que dificultam a uniformidade das ações. Aliados a esses fatores o território apresenta clima intertropical favorável à proliferação dos vetores e sofreu um processo de urbanização desordenada, por intermédio do qual cresceu boa parte das cidades brasileiras (JOHANSEN, 2014; PIMENTA, 2015; TAUIL, 2001). A emergência de cortiços e favelas sem 
quaisquer condições de atender às necessidades básicas de suas populações, como habitação e saneamento básico favorece a proliferação de vetores, impactando diretamente nas parcelas mais vulneráveis da população.

Ao vislumbrar a realidade brasileira frente a tríplice epidemia de arboviroses que acometeu o Brasil em meados de 2014 e dando ênfase ao caso do surto de Zyca Vírus, o estudo em tela revela que as políticas empregadas para conter a epidemiadesconsideram outras formas de contágio pelo vírus ${ }^{4}$ ou mesmo a determinação social da doença $^{5}$. Desta forma, não há indicadores de efetividade e eficiência dessas medidas (MERCHÁN-HAMANN, 1997). Compreende-se que estas ações por si só não são capazes de sanar os danos causados por uma epidemia desta proporção, como bem destaca Ventura (2016):

No Brasil, a securitização da resposta ao Zika fez do mosquito Aedes aegypti o maior inimigo da saúde pública. Porém, embora a "guerra contra o mosquito" seja necessária como providência imediata, ela não pode esconder que a lista de adversários da saúde é bem mais longa. Impõe-se a suspensão imediata de cortes orçamentários na área social, com a priorização de investimentos em saneamento básico e no fortalecimento dos SUS. Só um sistema de saúde eficiente pode garantir, quando finda a emergência, a continuidade da assistência às pessoas atingidas pela crise. Ademais, urge a implementação de uma agenda científica, com grande investimento em pesquisa e desenvolvimento (p.3).

Entende-se que o modelo de guerra ao mosquito aedes operado por Oswaldo Cruz e que conseguiu erradicá-lo na década de 1950 já não é capaz de operar os mesmos efeitos no atual contexto epidemiológico brasileiro em virtude da degradação ambiental e a acelerada urbanização que propiciou o aumento e adaptação do vetor em detrimento da extinção de seus predadores naturais ${ }^{6}$, que em tiveram seu habitat natural invadido pelo homem nas grandes cidades. Dessa forma, além da expansão e melhoria dos serviços de saúde faz-se necessário o investimento em infraestrura urbana, como saneamento básico e habitação de qualidade para a população. Diversos trabalhos (FERREIRA, et al, 2015; ABRASCO, 2016; NUGEM, 2015) revelam que o não acesso ou o acesso inadequado ao saneamento básico podem elevar os padrões de morbidade, especialmente nos casos relacionados as doenças transmitidas pelo aedes. Cabe também destacar que o financiamento dessa política, assim como da habitação popular se dá por intermédio da utilização de recursos do FGTS (Fundo de Garantia por Tempo de Serviço), sendo o Governo Federal o responsável por arrecadar e redistribuir os recursos desta fonte através de empréstimos destinados a companhias estaduais que controlam as operações neste segmento, o que dificulta a utilização destes recursos de forma a suprir as reias necessidades da população (ARRETCE, 2004).

A municipalização das políticas de habitação e saneamento básico não obtiveram o mesmo êxito das políticas de educação e saúde implementadas pelos municípios. Este fato se deve aos altos custos que envolvem a descentralização, ou ainda pela escassez de recursos para investimento em saneamento básico, ou pelo alto débito acumulado como é o caso da habitação (ARRETCHE, 2000). Desta forma, estas políticas seguem operando com maior centralização de poder decisório por parte da federação. O presente estudo aponta para a necessidade de intervir na "rede de acontecimentos" que influenciam a ocorrência de doenças dentro de um ambiente coletivo,

${ }^{4}$ Para maiores informações sobre outras de transmissão do ZYKV, ver OSTER, 2016.

${ }^{5}$ Entende-se que os estudos sobre a determinação social da saúde devem envolver a caracterização da saúde e da doença mediante fenômenos que são próprios dos modos de convivência do homem, um ente que trabalha e desfruta da vida compartilhada com os outros, um ente político, na medida em que habita a pólis, como afirmava Aristóteles (NOGUEIRA, p.10,2010).

${ }^{6}$ Considera-se predadores naturais do aedes: aranhas mosquiteiras, lagartixas de parede, libélulas, pássaros insetívoros, peixes guppy nos reservatórios de água, sapos, largatixas e outros répteis. a partir do conhecimento das reais condições de vida de um determinado lugar, o que origina o processo de determinação social da enfermidade (SANTOS, AUGUSTO, 2011). Em visto disto, percebe-se que estes aspectos são relegados a um segundo plano em virtude de discurso biomédico centrado no problema individual.

Ignorando a dimensão estrutural das epidemias o Estado adota a máxima de que os criadouros estão dentro de casa, assim cada indivíduo passa a ser o responsável único e direto pelo controle da epidemia e consequentemente pelo seu próprio adoecimento. Tal abordagem justifica ações restritas ao controle ao vetor, que afeta sobretudo as populações menos abastadas, tendo frequentemente suas residências fiscalizadas por Agentes de Combate as Endemias (ACE’s) (TAUIL, 2002), pois são esses atores os que estão em constante situação de vulnerabilidade (AUGUSTO, et al, 1998). Para Muller (2004), essa percepção focalizada do problema aponta para um caráter contraditório da política de combate à epidemia que amiúde desconsidera carências estruturais da população mais vulnerável e se apresentam impregnadas de juízos de valor por parte de seus formuladores, colocando em cheque a neutralidade das ações do Estado. Assim, entende-se que ao invés de considerarem as causas da proliferação do vírus em relação a causas estruturais como pobreza, habitação precária ou saneamento básico precário, as campanhas tendem a responsabilizar os indivíduos pelo contágio e proliferação da doença. Dessa forma, "essas campanhas exortam os indivíduos a assumirem responsabilidades por seu próprio bem-estar e prestam menos atenção na maneira como a posição social pode restringir as escolhas e as possibilidades das pessoas" (GIDDENS, 2012, p. 297). Neste sentido observa-se uma nítida atitude de desreponsabilização do Estado frente às questões estruturais imersas no contexto saúde-doença.

Em vista disto, compreende-se que a dinâmica do controle as arboviroses é definido por atores invisíveis, os chamados "especialistas", que estabelecem os rumos da agenda enfatizando a dimensão biológica do problema (CAPELLA, 2006). O desafio da análise destas políticas ultrapassa a mera compreensão das ações do Estado em si, mas passa pelas bases sob as quais se constrói a própria democracia (MULLER, 2004). No caso das campanhas de combate às doenças infectocongiosas, aqui no caso particular das arboviroses, também é importante destacar que o Sistema de Único de Saúde como um todo sofre grandes influências da concepção saúde-doença compreendida a partir do ponto de vista biológico, fato que finda por determinar o foco de ação das políticas públicas de saúde, embora não se possa menosprezar a biologia como campo de necessária intervenção e pesquisa. Neste sentido, a compreensão da PS como alternativa política no contexto das epidemias por arbovirus no Brasil torna-se salutar diante da necessidade de investimentos em ações que sejam capazes de mudar o contexto e a vida das populações mais atingidas por doenças, que o conceito de saúde ultrapasse a visão biológica e curativa da enfermidade e possa atuar na prevenção deste fenômeno através de mudanças estruturais que só serão possíveis através da interligação de vários campos de saberes e da conjugação de políticas econômicas e sociais com o objetivo de mudar essa realidade.

\section{CONSIDERAÇÕES FINAIS}

A partir do exposto entende-se que as epidemias por arbovirus acabam por revelar uma geografia perversa que revela os nexos invisíveis entre o adoecimento e as reais condições de vida de uma população. Assim, essa investigação revela que as campanhas e políticas públicas de controle ao vetor, ao estabelecerem como foco de intervenção o controle ao mosquito, acabam por obedecer a uma lógica mercantilista e biologista de pensar a saúde. Em virtude desta compreensão focalizada no vetor que ignora aspectos como a complexidade das doenças, incluindo as lacunas ainda existentes quanto ao seu diagnóstico, as dimensões continentais do território brasileiro, o clima intertropical, a deficiência em infraestrutura urbana, a precariedade dos serviços públicos de saúde e a descontinuidade das intervenções do poder público, as quais 
restringem melhores resultados a médio e longo prazo. Dessa forma, faz-se necessário discutir a lógica de controle aos vetores a partir do referencial teórico que alicerça as bases da Nova Promoção da Saúde no Brasil, ultrapassando nesse a lógica biomédica de compreensão do fenômeno e estabelecendo um vínculo profícuo entre as bases de reprodução da vida material em determinada sociedade e a saúde de sua população. Neste sentido, o estudo aponta a necessidade de concentrar ações que proponham o monitoramento contínuo das ações de combate aos vetores durante todo o ano, além de maior investimento público em ações de vigilância sanitária e epidemiológica, infraestrutura urbana, desenvolvimento de tecnologias que auxiliem no diagnóstico e tratamento da doença, além de mais pesquisas e estudos sobre o tema alicerçado nos paradigmas que fundam a NPS. Tendo em vista que a presente investigação tratarse de um estudo preliminar verifica-se a necessidade de um maior aprofundamento nas questões aqui colocadas, na medida em que mais informações teóricas e empíricas sejam disponibilizadas para uma análise das políticas públicas endereçadas a este problema.

Financiamento: $\mathrm{O}$ presente trabalho foi realizado com o apoio da Universidade Estadual da Paraíba, edital PRPGP 001/2021.

\section{REFERÊNCIAS BIBLIOGRÁFICAS}

Ministério da saúde. Secretaria de Vigilância em Saúde. Departamento de vigilância de doenças e agravos não transmissíveis e promoção da saúde. Resumo Executivo 2015/2016: uma análise da situação de saúde e da epidemia pelo vírus Zika e por outras doenças transmitidas pelo Aedes aegypti. Brasília, 2017. Disponível em: $<$ http://portalarquivos.saude. gov.br/images/pdf/2017/julho/17/2017-0146-SBREXC-online final.pdf>. Acesso em 19 jul. 2017.

Ministério da Saúde. Secretaria de Vigilância em Saúde. Monitoramento dos casos de dengue, febre de chikungunya e febre pelo vírus Zika até a Semana Epidemiológica 52. Bol Epidemiol. Brasília, v. 47, p.1-10. 2016

Saúde global: olhares do presente. Rio de Janeiro: Fiocruz, 2016.

ARRETCHE, 2004. Marta. Federalismo e Políticas Sócias no Brasil: problemas de coordenação e autonomia. Revista São Paulo em Perspectiva, vol.18, no2, p.17-26.

ASSOCIAÇÃO BRASILEIRA DE SAÚDE COLETIVA ABRASCO. 2016. Cidades sustentáveis e saudáveis: microcefalia, perigos do controle químico e o desafio do saneamento universal. Disponível em: <https://www.abrasco .org.br/site/2016/02/carta-de-alerta-da-abrasco-cidadessaudaveis-e-sustentaveis-este-e-o-desafio-urgente/ >. Acesso em: abr. 2017.

AUGUSTO, et al. 2016. Aedes aegypti control in Brazil. Correspondence. In: The Lancet.Volume 387, $\mathrm{n}^{\circ} 10023, \mathrm{P} 1052-$ 1053, 12 March.

AUGUSTO, L. G. S. et al. 1998. Programa de erradicação do Aedes aegypti: inócuo e perigoso (e ainda perdulário). Cadernos de Saúde Pública. 14 (4): 876-7.

BRASIL. 2016B. Ministério da saúde. Secretaria de vigilância em saúde. Ações realizadas para enfrentamento da emergência em saúde pública relacionada à microcefalia. Apresentação.

BREILH, Jaime; GRANDA, Edmundo (Tradução CAVALHEIRO, José da Rocha et al. 1989. Investigação da Saúde na Sociedade: guia prático sobre um novo enfoque do método epidemiológico. 2 ed. São Paulo: Cortez: Instituto de Saúde; Rio de Janeiro: Associação Brasileira de Saúde Coletiva (Coleção Pensamento Social e Saúde ;4).

BUSS, P. M. 2003. Uma Introdução ao Conceito de Promoção da Saúde. In: Promoção da Saúde: conceitos, reflexões, tendências. Rio de Janeiro: Editora Fiocruz.

CAPELLA, A. C. N. 2006. Perspectivas teóricas sobre o processo de formulação de políticas públicas. BIB, Revista Brasileira de Informação Bibliográfica em Ciências Sociais, v.61, p.20-40.

CORSICA, France. 2015. Zika virus transmission from French Polynesia to Brazil. Emerg Infect Dis, v. 21, n. 10, p. 1887.
DONALISIO, Maria Rita; FREITAS, André Ricardo Ribas; VON ZUBEN, 2017. Andrea Paula Bruno. Arboviroses emergentes no Brasil: desafios para a clínica e implicações para a saúde pública. Revista de Saúde Pública. 51: 30.

FERREIRA, H.M.R, et al. 2015. A política de racionamento de água na cidade do Recife, Brasil: impactos e desigualdades nos assentamentos precários. In: $\mathrm{O}$ direito à água como política pública na América Latina: uma exploração teórica e empírica. Editores: José Esteban Castro, Léo Heller, Maria da Piedade Morais. - Brasília : Ipea, 2015.

FLEURY-TEIXEIRA, Paulo. 2009. Uma introdução conceitual à determinação social da saúde. Saúde em debate, v. 33, n. 83.

FREITAS, A. R. R; VON ZUBEN, A. P. B; ALMEIDA, V. C. Informe técnico: zyca vírus. Devisa: Campinas - SP, 2016. Disponível em: <http://www.caism.unicamp.br/ PDF/Informe Tecnico_01_\%20ZIKA_VIRUS_jun_2016.pdf $>$ Acesso em: 02 mai. $20 \overline{17}$.

GIDDENS, Anthony. Sociologia. 6. ed. Porto Alegre: Penso, 2012.

GÓMEZ, C.M.; MINAYO, M. C.S. Enfoque ecossistêmico de saúde: uma estratégia transdisciplinar. In: CINTERFACEHS - Revista de Gestão Integrada em Saúde do Trabalho e Meio Ambiente v.1, n.1, Art 1, ago 2006.

JOHANSEN, Igor Cavllini. Urbanização e saúde da população: o caso da dengue em Caraguatatuba (SP). Dissertação (Mestrado). Programa de Pós-graduação em Demografia. Instituto de Filosofia e Ciências Humanas, UNICAMP. Campinas-SP, 2014.

LABRA. M. E. O Movimento Sanitarista dos anos 20: da conexão sanitária internacional à especialidade em saúde pública no Brasil [dissertação]. Rio de Janeiro: Fundação Getúlio Vargas; 1985.

MARTINS, Rodrigo. O Zika e o descaso da saúde pública. CARTA CAPITAL.15/02/2016.Disponívelem:https://www.cartacapital.c om.br/revista/886/e-haja-mosquitos. Acesso em: 09 de out. de 2017.

MINISTÉRIO DA SAÚDE E SECRETÁRIAS ESTADUAIS DE SAÚDE. 2016. Novo informe do Ministério da Saúde com os casos de microcefalia associada ao Zika Vírus. Disponível em: http: <www.saudedoviajante.pr.gov.br/2016/03/30/Novoinforme-do-Ministerio-da-Saude-com-os-casos-de-microcefaliaassociada-ao-Zika Virus.html>. Acesso em: 02 fev. 2018.

MULLER, Pierre e SUREL Yves. A análise de políticas públicas. Educat, Pelotas, 2004, p. 09-32.

NUGEM, C, R. Doenças relacionadas ao saneamento ambiental inadequado (DRSAI). Dissertação (mestrado) - Universidade Federal do Rio Grande do Sul, Escola de Enfermagem, Programa de pós-graduação em saúde coletiva. Porto Alegre. 2015.

NUNES, Everardo Duarte (org). Juan César Garcia: pensamento social em saúde na América-latina. São Paulo: Cortez, 1989.

PIMENTA, Denise Nacif; CUNHA, Ricardo Venâncio de (orgs.). Dengue: teorias e práticas. Rio de Janeiro: Editora Fiocruz, 2015, p. 75-92.

RIBEIRO, H. Saúde Pública e Meio Ambiente: evolução do conhecimento e da prática, alguns aspectos éticos. In:Saúde e Sociedade v.13, n.1, p.70-80, jan-abr 2004. Disponível em: $<$ http://www.scielo.br/pdf/sausoc/v13n1/08.pdf $>$. Acesso em: 02 de março de 2018.

SANTOS, L. S; AUGUSTO, S, G, L. Modelo multidimensional para o controle da dengue: uma proposta com base na reprodução social e situações de risco. Revista de Saúde Coletiva. Rio de Janeiro, v. 21, n. 1, p. 177-196. 2011.

SÃO PAULO. Secretária do Estado de São Paulo. Boletim Epidemiológico de 06/03/2018. Disponível em: http://www.saude.sp.gov.br/resources/cve-centro-de-vigilanciaepidemiologica/areas-de-vigilancia/doencas-de-transmissao-porvetores-e zoonoses/doc/famarela/fa18_boletim_epid_0603.pdf. Acesso em: 13 de março de 2018.

SOUZA, Celina. Governos locais e gestão de políticas sociais universais. Revista São Paulo em Perpectiva, vol. 18 n²:p. 2741, 2004.

TAUIL, Pedro Luiz. Urbanização e ecologia do dengue. São Paulo: editora Cortez, 2001. 
VASCONCELOS, Pedro Fernando da Costa. Doença pelo vírus Zika: um novo problema emergente nas Américas? Revista PanAmazônica de Saúde, v. 6, n. 2, p. 9-10, 2015.

VENTURA, Deisy de Freitas Lima. From Ebola to Zika: international emergencies and the securitization of global health. Cadernos de saúde publica, v. 32, n. 4, 2016.
WESTPHAL, M.F.; promoção da saúde e a qualidade de vida. FERNANDEZ, J.C; MENDES, R. (ORGS). Promoção da saúde e gestão local. SÃO PAULO: ADERALDO \& ROTHSCHILD, 2007. (SÉRIE SAÚDE EM DEBATE).

$* * * * * * *$ 